\title{
Analysis of the Thermal Load of Structural Elements High-Power DC Supply with the Transformer of Ripple Filter with Current Overload
}

\author{
Lokvenc Jaroslav, Drtina Rene and Sedivy Josef \\ Department of Technical Subjects, Faculty of Education, University of Hradec Kralove, Rokitanskeho 62, 50003 Hradec Kralove, Czech \\ Repubilc
}

\begin{abstract}
Design of the high-power DC supply quite logically based on the required electrical parameters and expected or defined operating conditions. A prerequisite trouble-free operation is also the correct choice of construction materials. Both in terms of mechanical strength and stability, and in terms of thermal load. The article deals with thermal conditions in the high-power DC supply with the transformer of ripple filter for long-term current overload.
\end{abstract}

\section{Introduction}

High-power DC supplies for industrial purposes are designed completely differently from conventional commercial devices. For industrial devices usually do not mind larger size or heavier.

The primary requirement is virtually maintenance free operation and operational reliability. A ommon requirement is too high short or long term overload. Short time overload DC supplies depend primarily on the data of the rectifier elements. Long-term overload is further more also dependent on the thermal resistance of materials used in the construction of source solution a thermal bridge and cooling space of the individual components and the entire DC supply.

Used model solution based is on theoretical knowledge of key publications [1]-[3] and the results of long-term practical tests.

\section{High-power DC supply with high current overload}

Tree-phase high-power DC supplies with the transformer of ripple filter for industrial purposes [4]-[6] designed for heavy-duty applications. DC supplies of this construction are primarily designed for power series motors with heavy start and, as a starting source for internal combustion engines and for power supply for small railways, trolley, electroplating, etc.

The prototype linear stabilized power supply to heavy operating conditions, the output current voltage characteristic is comparable to the current voltage characteristic of lead-acid battery was developed in the laboratories of the Department of electro technical subjects, Faculty of Education, University of Hradec Kralove. His scheme is to Fig. 1.

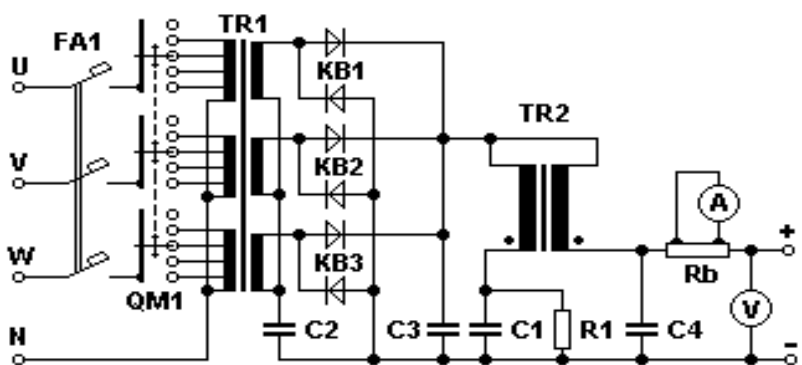

Figure 1. Scheme of the high-power DC supply 14V/140A.

Source is designed for permanent load 140A with the expected short-term overloading (in the order of minutes to tens of minutes) at $50 \%$ of rated current. Peak overload (for example, when starting production engines) is $100 \%$ for a few seconds. Overloading sources represents, among others, increased heat stress key components. The power dissipation and thereby heat generation of increases with the square of the current (Eq. 1)

$$
P_{\text {dissip }}=R_{\text {dissip }} \cdot I^{2}
$$

$R_{\text {dissip }}$ represents an undesirably loss resistances in the circuit and $I$ through the current. At $50 \%$ overload is therefore greater power dissipation of $125 \%(2.25 \times)[1,3]$. At $100 \%$ overload is then dissipated power four times higher than in normal operation. The most critical places with the greatest heat stress are a transformer TR1 [2], half-bridges rectifiers $\mathrm{KB} 1, \mathrm{~KB} 2, \mathrm{~KB} 3$ and secondary windings of the transformer TR2, through which the DC output current. Power dissipation naturally grows on the connecting wires, at the measuring resistor $\mathrm{Rb}$ and on the transient resistances of the output terminals (Fig. 1).

The modern half-rectifier bridges with metal base and structure have isolated when mounted correctly minimal 
thermal resistance and of adequate size cooler is a big factor in restrictive maximum forward current $I_{\mathrm{FSM}}$ and the Limiting integral $I^{2}$ t.overload. Permissible operating surface temperature of modern diodes and rectifiers is normally up to $95^{\circ} \mathrm{C}$.

\section{Thermal resistance in transformers}

Power dissipation in the transformer overloaded arises particularly in the winding, so called in losses copper. Transformers cooled by natural convection transfer heat the surface of the core and surface winding. Armature coils, insulation and covering layers represent heat bridges with large thermal resistances, which greatly limits the transmission and radiation of heat [1], [3] (Fig. 2).

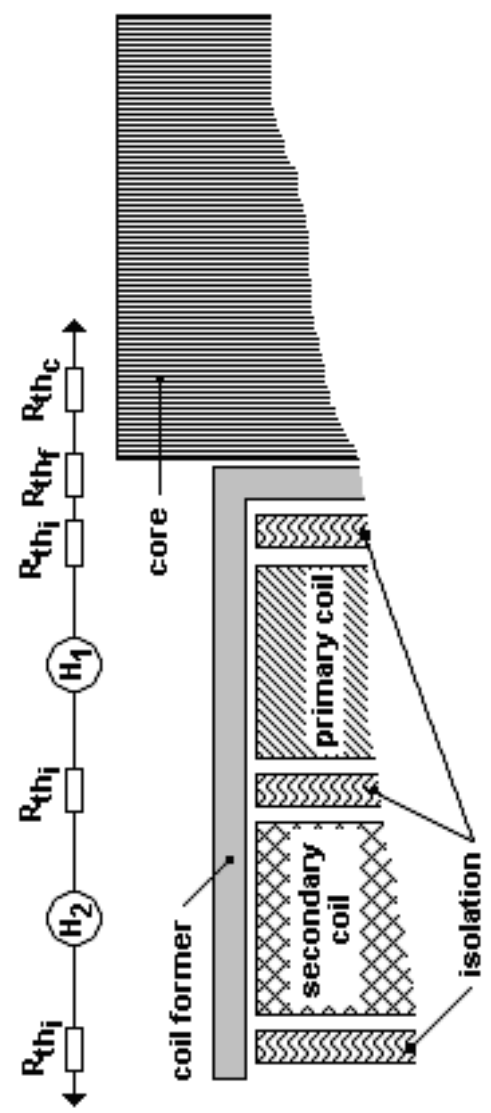

Figure 2. Simplified scheme of heat flows in the transformer.

The heat generated in the primary and secondary windings $\left(\mathrm{H}_{1}, \mathrm{H}_{2}\right)$ (Fig. 2$)$ is first accumulated in the mass of the winding. Despite the isolation $\left(\mathrm{R}_{\text {thi }}\right)$ and coil former $\left(R_{t h f}\right)$ only slowly penetrates to the core of it and passes into the atmosphere $\left(\mathrm{R}_{\mathrm{thc}}\right)$. On the other hand, passes the heat to the atmosphere through the outer insulating layer $\left(\mathrm{R}_{\text {thi }}\right)$. Heat flow between $\mathrm{H}_{1}$ and $\mathrm{H}_{2}$ through the insulating layer $\left(\mathrm{R}_{\mathrm{thi}}\right)$ is always in the direction of the temperature gradient.

From the structural design of the transformer can be inferred that the larger cooling surface of the nucleus and thus less thermal resistance of the core have the transformers with core sheathing (EI transformers). Core transformers (for example UI/UN, C-core and toroidal transformers), by contrast, have a greater cooling surface coils [2], [3]. Warming of the transformer core and windings during normal operation can be determined from Eq. 2 and Eq. 3 [3]

$$
\begin{gathered}
\Delta \theta_{\text {core }}=P_{\text {core }} \cdot R_{\mathrm{th}_{\mathrm{c}}}=\frac{P_{\text {core }}}{c_{\text {core }} \cdot F_{\text {core }}} \\
\Delta \theta_{\text {coil }}=P_{\text {coil }} \cdot R_{\mathrm{th}_{\mathrm{i}}}=\frac{P_{\text {coil }}}{c_{\text {coil }} \cdot F_{\text {coil }}}
\end{gathered}
$$

where is $\Delta \theta_{\text {core }}$ warming of core, $R_{\text {thc }}$ thermal resistance of core, $P_{\text {core }}$ power dissipation of core, $c_{\text {core }}$ cool down constant of core, $F_{\text {core }}$ cooled surface of core, $\Delta \theta_{\text {coil }}$ warming of coil, $R_{\text {thi }}$ thermal resistance of external insulation, $P_{\text {coil }}$ power dissipation of coil, $c_{\text {coil }}$ cool down constant of coil, $F_{\text {coil }}$ cooled surface of coil. When the transformer overload significantly grows in power dissipation coil, power dissipation of the core remains by [3] virtually the same.

\section{Thermal load elements of an overloaded high-power supply}

Operational testing of a prototype high-power DC supplies with the ripple filter transformer of $14 \mathrm{~V} / 140 \mathrm{~A}$ (Fig. 1) implemented by our proposal [5] include, among other things, test the temperature rise during overload. The source was burdened by a steady stream $210 \mathrm{~A}$, which is overloaded by $50 \%$ on nominal current. Was Measured temperature coil, coil surface temperature and core temperature on transformer T1, temperature on base halfbridges rectifiers and cooler temperature, coil temperature and core temperature on T2 transformer, shunt resistor amperemeter temperature, temperature wires and output terminals temperature.

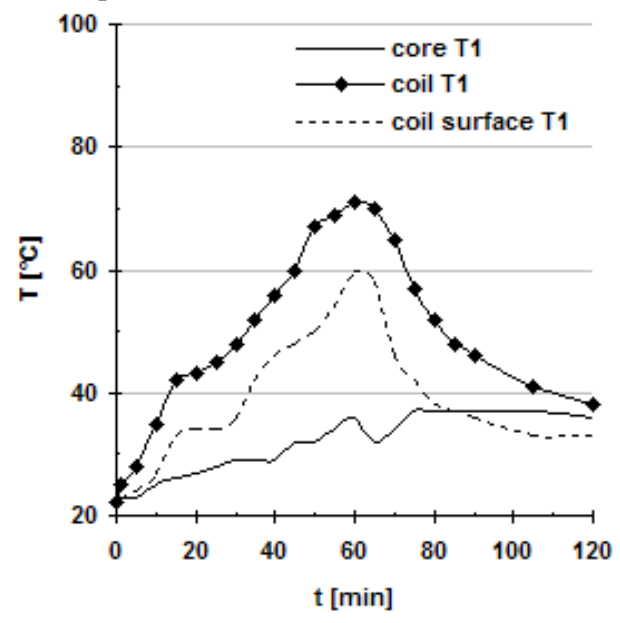

Figure 3. Temperature variation of source overload and after switch off - Transformer T1.

Overload test was limited to a maximum duration of one hour or violation of any of the temperature limit: $90^{\circ} \mathrm{C}$ for coil temperature, $95^{\circ} \mathrm{C}$ for base half-bridges rectifiers temperature, $105^{\circ} \mathrm{C}$ for shunt amperemeter resistor temperature and $70^{\circ} \mathrm{C}$ for wires temperature. We were monitored and output terminals temperature, but for the test was not limiting. Maximal temperature of output terminals is $110^{\circ} \mathrm{C}$, which is much higher than the 
permissible temperature of the connecting wires. After turning off the power for 1 hour monitored temperatures drop all parts source. Measurement of results is plotted in Fig. 3.

From the measured values it is clear that at ambient temperature up to $25^{\circ} \mathrm{C}$ are not exceeded any limits during sustained overload for 1 hour. Heat the most affected element is a three-phase source threecolumns transformer T1, which accumulates most of thermal energy. From the graph it is evident that after turning off the source of heat is accumulated in the transformer winding is transferred to the core and the core temperature rises further.

The transformer T1 due to the small cooling surface of the core and a relatively small cooling surface coils cools slowest. At $24^{\circ} \mathrm{C}$ was cooled to $4 \frac{1}{2}$ hours after the power is turned off (Fig. 3).

In contrast, the compensation transformer TR2 with single-layer winding and a large cooling surface is heated considerably more slowly and more rapidly cool (Fig. 4).

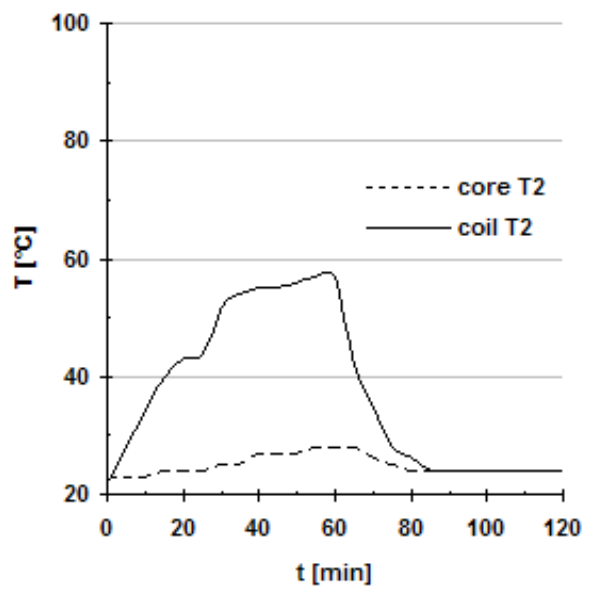

Figure 4. Temperature variation of source overload and after switch off - Transformer T2.

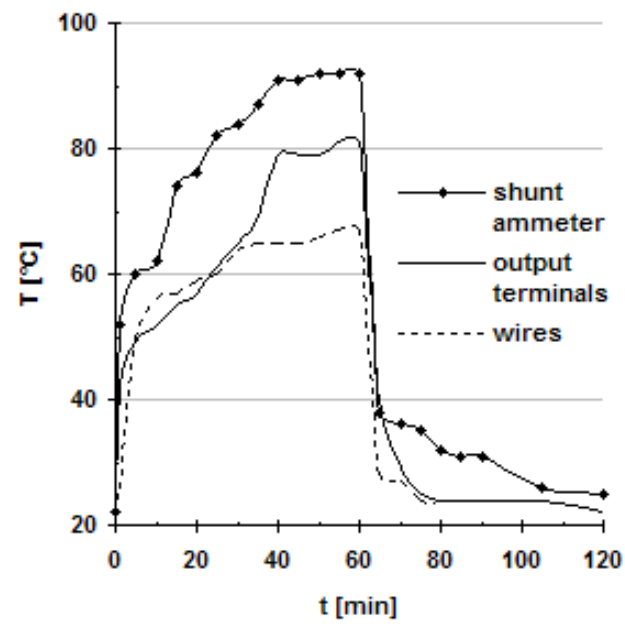

Figure 5. Temperature variation of source overload and after switch off - Shunt ammeter, internal wires, output terminals.

The graph (Fig. 5) indicates that the fastest cools amperemeter shunt resistor, wires and output terminals. Current load of the internal wires and output terminals were $8,4 \mathrm{~A} / \mathrm{mm}^{2}$.

The amperemeter shunt resistor is designed for a current of $250 \mathrm{~A}$ and therefore not overloaded. The maxi- mum operating temperature for the amperemeter shunt is by the manufacturer determined on $155^{\circ} \mathrm{C}$.

Temperatures half-bridges rectifiers and coolers after the power is turned off within 20 minutes aligned and cold as well (Fig. 6).

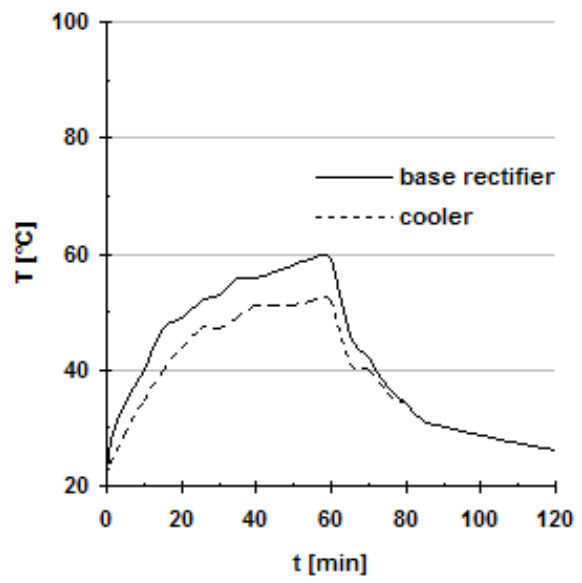

Figure 6. Temperature variation of source overload and after switch off - Transformer T2.

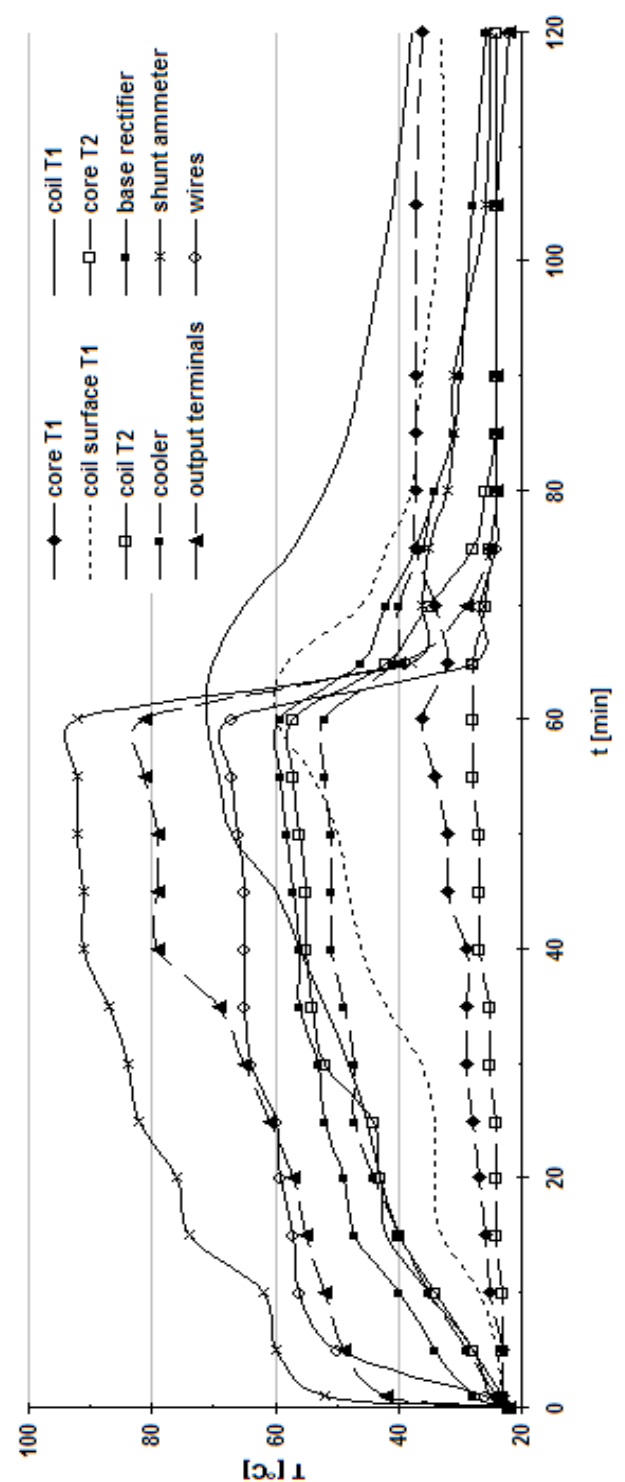

Figure 7. Temperature variation of source overload and after switch off - Summary graph. 
Comprehensive summary graph of temperature measurements of the overloading power supply is on Fig. 7.

\section{Summary}

Of course readings, we can deduce that our proposed resource withstands significant long-term overload. Key elements of the well withstand the same overload even at ambient temperatures of $40^{\circ} \mathrm{C}$, except for the connecting conductors, which would have to be dimensioned either to a higher operating temperature or at lower current density and less computational warming. For ambient temperature of $40^{\circ} \mathrm{C}$ can be assumed linear movement of the thermal characteristics of the transformer T1 and significantly longer cooling period.

Measurements of the prototype high-power DC supplies with the transformer of ripple filter showed that the transformer sources are also currently its substance and that even with a relatively simple design, achieving very good performance and withstand even long-term overload. Due to easy handling, high durability and high operational reliability can be easily used in automated processes

The article was prepared with the support of specific research project SV PdF 2018/2012 - High-power DC supply with mid-frequency transformer compensation ripple voltage with high-overload current.

\section{References}

1. J. H. Harlow. Electric power transformer engineering. BOca Raton, CRC (2007).

2. J. J. Winders. Power transformers: principles and applications. New York, Dekker (2002).

3. Z. Faktor. Transformer and coils. Praha, BEN (1999).

4. R. Drtina, J. Lokvenc and J. Andris. The Accessories for Your Laboratories, Part 9. - Switching supply for laboratory use, Media4u Magazine, 1, pp.55-62, (2009).

5. J. Lokvenc, R. Drtina. Power supply voltage with the transformer ripple filter, in: The 11th WSEAS/ IASME International Conference on Electric Power Systems, High Voltages, Electric Machines, Penang, Malaysia, pp.60-64, (2011).

6. J. Lokvenc, R. Drtina, and M. Sobek. Three-phase high overload DC power supply voltage with the mid-frequency transformer ripple filter. In The 12th WSEAS International Conference on Electric Power Systems, High Voltages, Electric Machines, Praha, pp.29-34, (2012). 